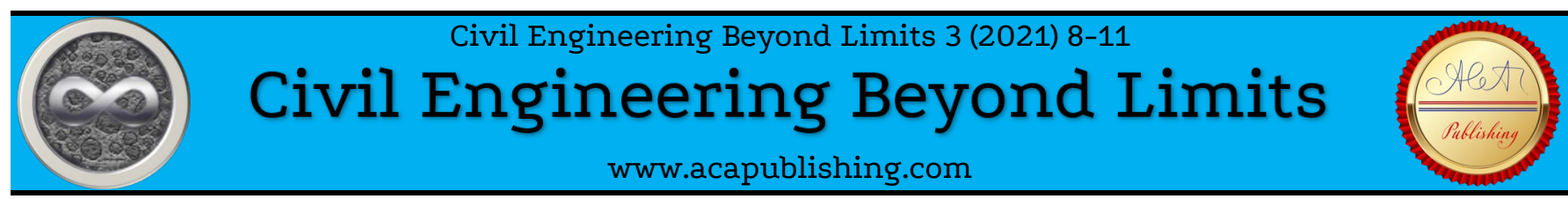

Research Article

\title{
Some Geotechnical Properties of Clay Soil Enhanced with Silica Fume
}

\author{
Ahmed M. Al-Khalili, Ahmed S. Ali, Abbas J. Al-Taie* \\ Al-Nahrain University, College of Engineering, Civil Engineering Department, Baghdad, Iraq
}

\section{Keywords}

Theoretical geotechnical properties,

Clay soil,

Consolidation parameters,

Problematic soils,

Silica fume.

\begin{abstract}
Engineering structures found in, or on, some clay soil types may be subject to different damages due to the problematic nature and unfavorited properties of these soils. The unfavorited properties of these soils include shrink and swell changes, high settlement, and low bearing capacity. These soils have high sensitivity to moisture change. The way to reduce or overcome the unfavorited properties of problematic soils is the treatment or enhancement of these soils using different mechanical or chemical methods. In the present paper, silica fume selected as a soil stabilizer material, the effect of different contents of this material on the geotechnical properties of expansive clay soil has been experimentally investigated. Tests included soil specific gravity, soil plasticity, soil compaction, and soil compressibility. It was noted that silica fume, with different contents, decreased the specific gravity, and compaction density, while the compaction water content and Atterberg limits increased. The consolidation parameters of the expansive clay soil were affected by adding the silica fume. The silica fume reduced the consolidation parameters values of the clay soil. At low content silica fume, less than $10 \%$, a very slight reduction can be seen especially for the rebound index value. The final findings of this paper appeared that the high settlement of clay soil can be reduced with the presence of silica fume.
\end{abstract}

\section{Introduction}

Some clay soil types have unfavorited properties that make these soils problematic in nature. These soils undergo large volume changes and unacceptable settlement values when the seasonal changes in water table level happened. The unfavorited properties of these soils are mainly due to their mineral composition and their plasticity. The wetting and drying cycles that happen during the rainy and drying seasons make clay soils sticky and subject them to cracks. As a result, different problems are resultant which can cause damages to engineering-structures especially light building, roads, retaining structures, the bed of canals, etc, [1-6]. The resolving of the problems of clay soils can be achieved using stabilization techniques using different additives (e.g. cement, cement dust, lime, flyash, stone dust, ceramic dust, and etc.) or with the assistance of mechanical means (e.g. surcharge method, compaction control, soil replacement, prewetting method, installation of moisture barriers, and soil reinforcement method) [7-10].

The use of by-product materials in stabilization clay soils has different economic, environmental, and geotechnical benefits. Among these materials is silica fume, this material is produced by smoke condensation in the production processes of ferrosilicon metal [11-13] The effect of silica fume on soil properties is reviewed in the literature. The swelling pressure of the cohesive soil was inversely proportional to the amount of silica fume, as the amount of this material increased from $5 \%$ to $15 \%$ the swelling pressure reduced by about $90 \%$ [13-14]. The strength of soils treated with silica fume is directly proportional to the amount of this material [15-16]. According to Kalkan and Akbulut (2004) [16] the permeability of the silty clay soil decreased as the content of silica fume increased from $5 \%$ to $10 \%$. The physical properties of soils are affected by the addition of silica fume to these soils. Properties like specific gravity, Atterberg limits, dry density are decreased while properties like optimum water content increased with increasing the amount of silica fume $[13,15,147]$. In contrast to these studies, Bharadwaj and Trivedi (2016)[18] found that the addition of micro silica fume increases the values of optimum water liquid limit, shrinkage limit, and soil plasticity. It was discovered that the addition of silica fume reduces the free swell and swelling potential of the soils $[13,17]$. The incorporation of silica fume with other additives, e.g. lime, has great effects on the soil bearing values of compacted clay as stated by Al-Hassany (2014) [17].

Almost, the application of silica fume in soil stabilization was widely used. Most of the published papers focused on properties such as density and water content, Atterberg limits, soil strength, bearing ratio, swelling pressure, and swelling potential. Little attention has been given to soil compressibility and consolidation parameters. On the other hand, one can be noted that there is a contrast in the effect of silica fume on properties like liquid limit, soil plasticity, and compaction water content, some references showed increasing in these properties while other references showed a decrease in these properties.

As a result, such situations necessitate experimental investigation to study the effect of silica fume on soil compaction, Atterberg limits, and its consolidation parameters. In this paper, the effect of adding different silica fume contents on the specific gravity, compaction properties, Atterberg limit, and consolidation of clay soil has been investigated. A series of compaction test, Atterberg limits test, and consolidation test has been conducted on clay soil treated with silica fume. The samples of clay soil were prepared by adding $5 \%, 10 \%$, and $15 \%$ of silica fume and tested according to the ASTM specifications.

\section{Materials and experimental tests}

The silica fume is the selected soil stabilizer in this paper. By condensed the smoke raised from the production operation of the ferrosilicon metal in the electric furnaces, this material made. It has particles of a spherical shape softer than cement; it is a fine-grained material. The specific gravity of the silica fume used is 2.3. it is a dark grey material that consists mainly of silica (about $90 \%$ of the chemical composition). 
The soil of this paper was prepared from the combination of $80 \%$ kaolin soil with $20 \%$ bentonite soil. It is high plasticity soil with a liquid limit of $67 \%$ and a plasticity index of $38 \%$. Its specific gravity is 2.67. According to the basic properties, the tested soil can be classified as a fat clay "CH" as per ASTM D2487 [19]. The location of soil testing on the plasticity chart is shown in Fig.1.

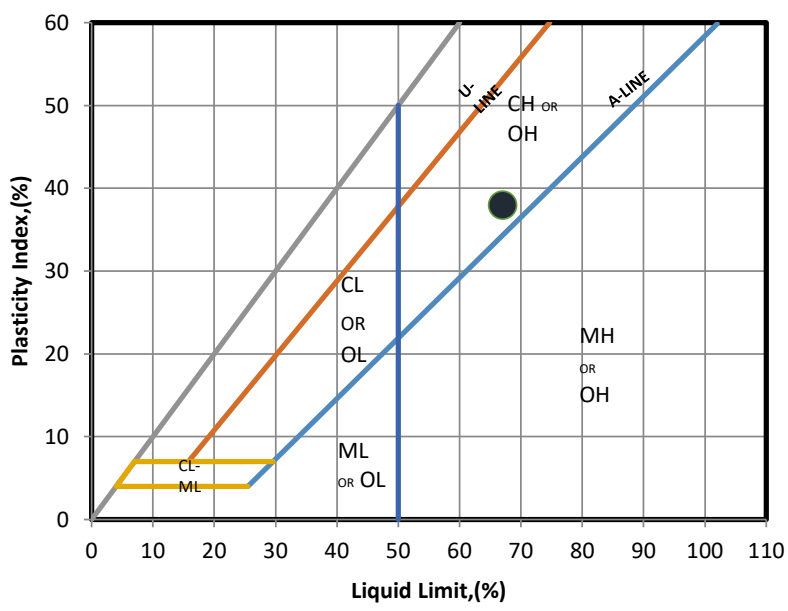

Figure 1. Location of the soil tested on plasticity chart

The experimental testing in this paper started with conducting standard compaction as per ASTM D698 [20]. The clay soil samples were compacted according to the standard proctor test to determine the maximum density and the optimum water content, the maximum density of the soil is $1.4 \mathrm{~g} / \mathrm{cm} 3$ and optimum water is $28.9 \%$.

The experimental program carried out consists of the determination of the specific-gravity (depending on the ASTM D-854 [21]), the Atterberg limits (tested according to ASTM D 4318 [22]). Finally, the consolidation test of the clay soil was investigated without and with silica fume. The soil samples and different contents of silica fume were mixed (soil: silica fume, 95\%:5\%, 90\%:10\%, and, 85\%:15\%). Firstly, the dry materials have been mixed, then water has been added to obtain the wet mixture. After that, the mixture compacted. To obtain the purpose of this paper, a series of one-dimensional consolidation tests has been carried out on the soil-silica fume specimens using front-loading standard oedometer device, the test as per ASTM standards [23]. The samples were subjected to incrementally applied controlled-stress loading. The loads used were applied at the following increments: $(2.5,25,50,100,200$, and 400$) \mathrm{kPa}$, and two unloaded steps $(400,100$, and 25$) \mathrm{kPa}$. The applied stresses are maintained until excess-pore water is dissipated.

\section{Test results and discussion}

\subsection{Specific gravity and Atterberg limits}

Fig. 2 shows the variation of clay-specific gravity with different amounts of silica fume. As shown, the silica fumeg with its low unit weight 9 decreased the clay-specific gravity. This is, in fact, consonant with the finding of the other researchers $[13,15,17]$.

The effect of silica fume content on the values of liquid and plastic limits, and plasticity index are illustrated in Fig. 3. It appears that the values of all limits are directly proportional to the silica fume content. As the silica fume content increased from 0 to $15 \%$, the liquid and plastic limits and the plasticity index increased. This is compatible with a finding of Bharadwaj and Trivedi (2016) [18], on one hand, and contrast with the results of Abass (2013) and Al-Hassany (2014) [17].

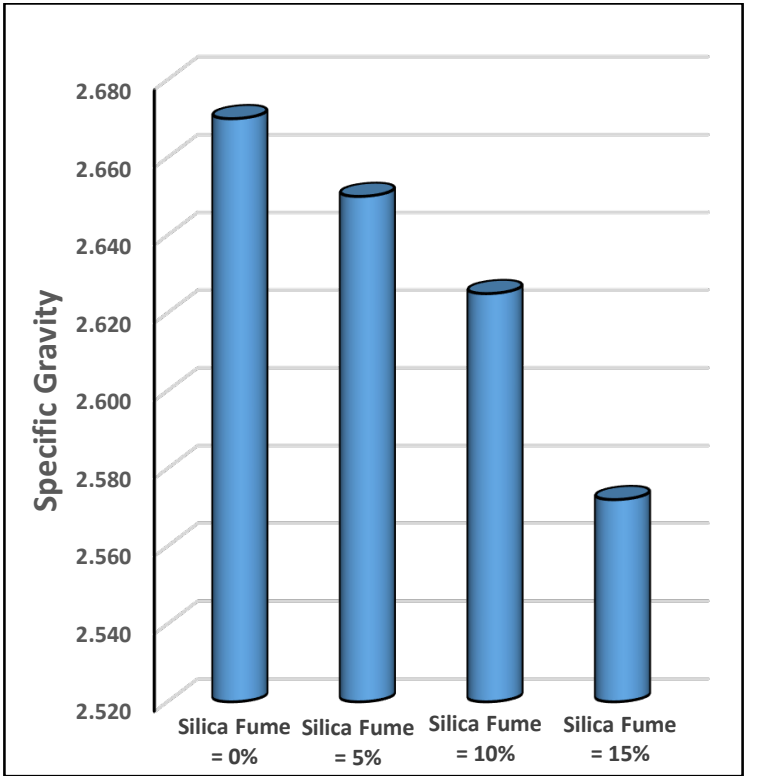

Figure 2. Effect of silica fume on the clay soil's specific gravity

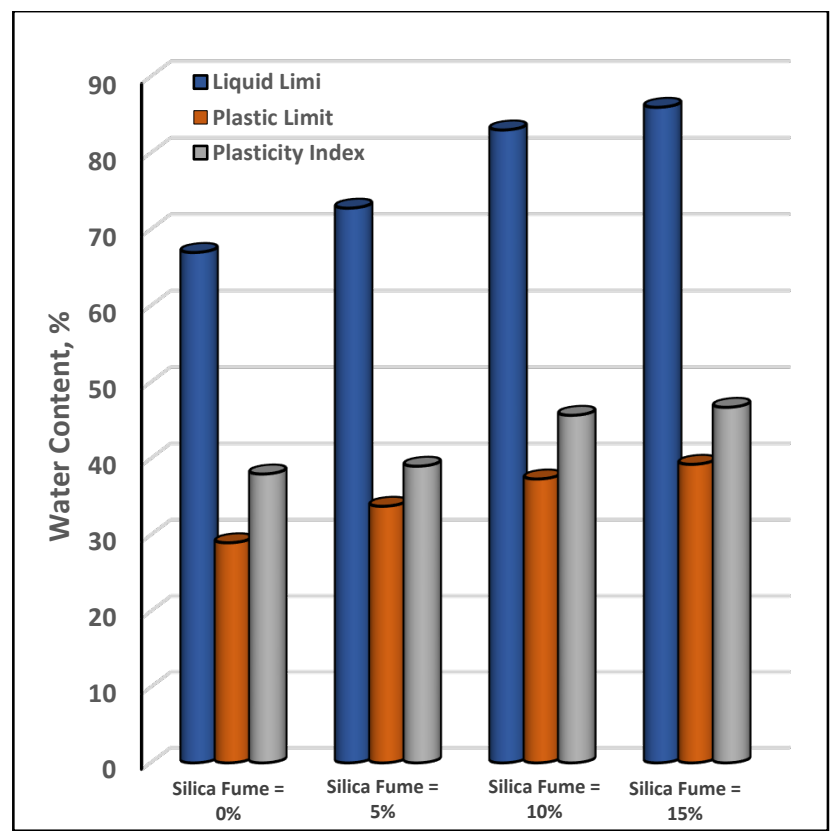

Figure 3. Effect of silica fume on Atterberg limits

\subsection{Compaction properties}

The effect of silica fume on the compaction behavior and properties of the clay soil is presented in Fig. 4. As shown in this figure, the silica fume has no effect on the shape of the compaction curve of the clay, the initial increase in dry density can be noted by increasing the compaction water content, with and without silica fume, up to the maximum value (the optimum value), then the dry density tends to decrease with further increase in molding water content. On the other hand, Fig. 4 shows a decrease in dry density with increasing silica fume content, while the optimum compaction water content of clay increases as the content of silica fume increased. This finding compatible with what found by researchers $[13,15,17]$. 


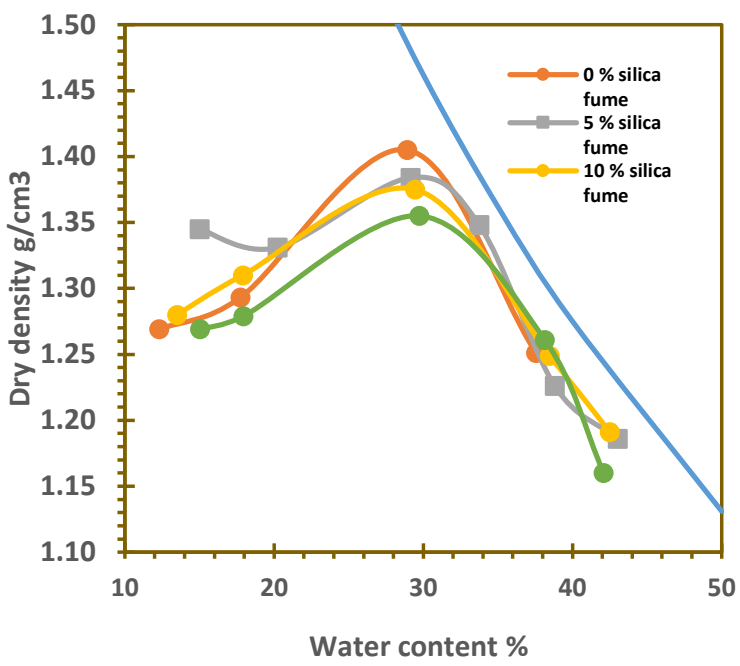

Figure 4. Effect of silica fume on compaction behavior and properties of clay soil

\subsection{Consolidation properties}

The results of the consolidation test have been used to plot the void ratio (in normal scale) with a variation of the applied stress (in a semilogarithmic scale) as presented in Fig. 5. These consolidation curves shown in Fig. 5 have been used to obtain the consolidation parameters of clay soil. Fig. 6 presents the effect of silica fume on the compressibility of the clay soil, the consolidation parameters (i.e. compression index (Cc) and rebound index (Cr)). The effects of silica fume on the clay soil's behavior are reflected by the effect of this material on compression index (Cc) and rebound index $(\mathrm{Cr})$ values, In Fact, soil with the compression index $\mathrm{Cc}$ and rebound index $\mathrm{Cr}$ has less tendency to settlement and verse-versa. As present in Figure 6 the silica fume has an important effect on the rebound index values of clay soil. The general trend reveals that the silica fume reduces the consolidation parameters values of the clay soil. At low content silica fume, less than $10 \%$, a very slight reduction can be seen especially for the rebound index value. With a further silica fume content, the consolidation parameters were decreased, the reduction in these parameters looks nonlinear in behavior. This may be due to the increase in the cation concentration where the thickness of the diffuse double layer reduced resulting in flocculating the clay particles and leading to a decrease in soil compressibility.

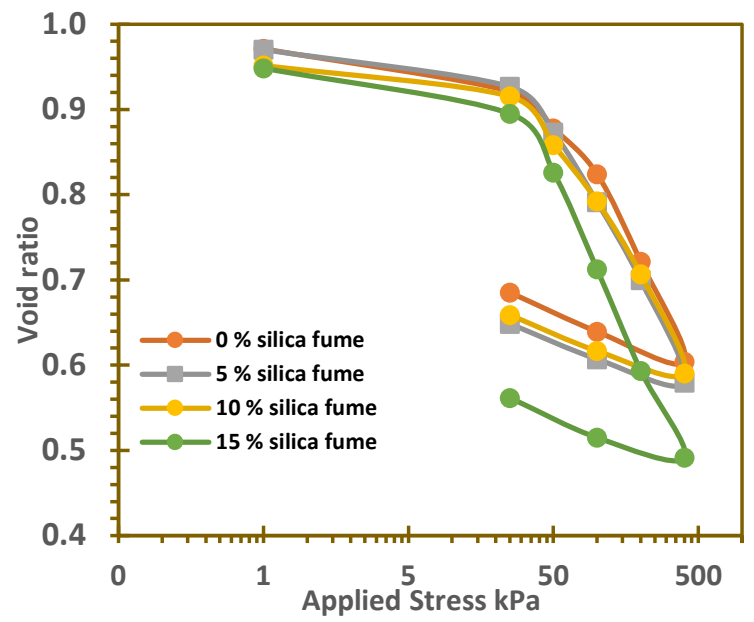

Figure 5. Effect of silica fume on consolidation curves

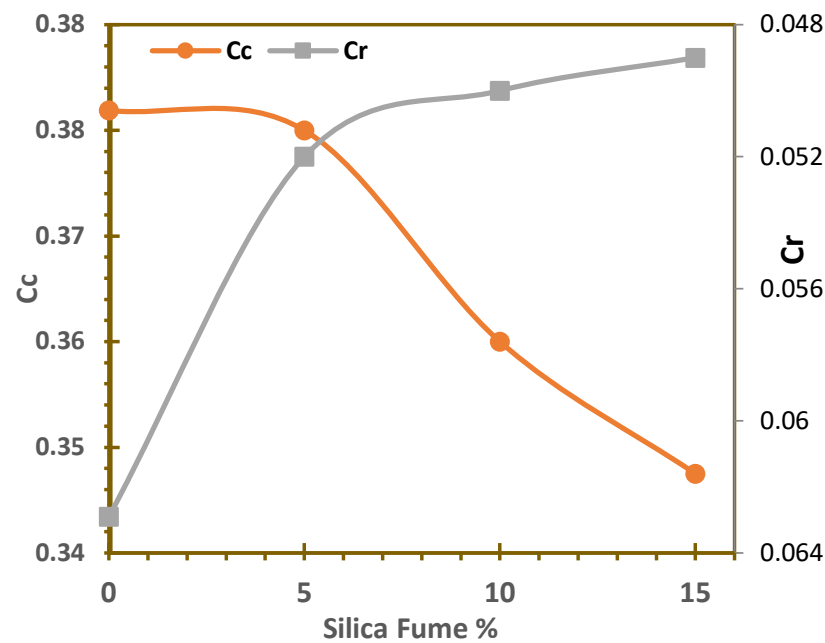

Figure 6. Effect of silica fume on consolidation curves

\section{Conclusion}

Silica fume improves some of the physical and engineering properties of soils, including, compaction properties, soil permeability, soil strength, and bearing values. This is well presented in the previous studies. In this work, a series of specific gravity test, compaction test, Atterberg limits test, and consolidation test has been conducted on clay soil treated with silica fume. The samples of clay soil were prepared by adding $5 \%, 10 \%$, and $15 \%$ of silica fume and investigated experimentally.

It was demonstrated that the shape of compaction curves of the clay soil seems not affected by silica fume addition. A decrease in dry density with increasing silica fume content was denoted, while the optimum compaction water content of clay increased as the content of silica fume increased. The values of all Atterberg limits were directly proportional to the silica fume content, while the specific gravity was inversely proportional to the content of this material. The silica fume has an effect on the compressibility of clay soil. The general trend of consolidation parameters revealed that the silica fume reduces the consolidation parameter values of the clay soil. At low content silica fume content, less than $10 \%$, a very slight reduction can be seen especially for the rebound index value. With a further silica fume content, the consolidation parameters were decreased, the reduction in these parameters looks nonlinear in behavior.

\section{Declaration of Conflict of Interests}

The authors declare that there is no conflict of interest. They have no known competing financial interests or personal relationships that could have appeared to influence the work reported in this paper. 


\section{References}

[1.] Nelson, J., Miller, D., Expansive soils problems and practice in foundation and pavement engineering. John Wiley and Sons, Inc., (1992)

[2.] Al-Baidhani, A., Al-Taie, A., Review of brick waste in expansive soil stabilization and other civil engineering applications. Journal of Geotechnical Studies 4(3) (2019) 14-23.

[3.] Al-Baidhani, A., Al-Taie, A. J., Shrinkage and strength behavior of highly plastic clay improved by brick dust. Journal of Engineering (Eng. J.) 26 (5) (2020a) 95-105.

[4.] Al-Baidhani, A., Al-Taie, A. J., Recycled crushed ceramic rubble for improving high expansive soil terephthalate in improving poorly graded soil. Transportation Infrastructure Geotechnology. 7 (2020b). https://doi.org/10.1007/s40515-020-00120-z.

[5.] Chen, F.H., Foundation on Expansive Soils. Elsevier Scientific Publishing Company, Amesterdam, (1975).

[6.] Murthy, V.N.S., Geotechnical Engineering: Principles and Practices of Soil Mechanics and Foundation Engineering. CRC press, (2002)

[7.] Hussein, A., Ali, A., Al-Taie, A., A review on stabilization of expansive soil using different methods. Journal of Geotechnical Engineering 6(3) (2019) 32-40.

[8.] Al-Naje, F.Q., Abed, A.H., Al-Taie, A.J., Improve geotechnical properties of soils using industrial wastes: A review. Civil Engineering Beyond Limits 4 (2020) 28-34.

[9.] Al-Naje, F.Q., Abed, A.H., Al-Taie, A.J., Compaction characteristics of natural cohesive subgrade soil stabilized with local sustainable materials. IOP Conference Series Materials Science and Engineering 1105 (2021).

[10.] Hussein, A., Ali, A., Al-Taie, A., Some geotechnical properties of plastic soil enhanced with cement dust. Journal of Engineering (Eng. J.) 27 (2021).

[11.] Al-Naje, F.Q., Abed, A.H., Al-Taie, A.J., A review of sustainable materials to improve geotechnical properties of soils. Al-Nahrain Journal for Engineering Sciences $23 \quad 3$ (2020) 289-305. https://doi.org/10.29194/NJES.23030289.

[12.] Nita, C., John, V.M., Dias, C.M.R., Savastano, J.R.H., Takeashi, M.S., Effect of metakaolin on the performance of pva and cellulose fiber reinforced cement. Proceedings of $17^{\text {th }}$ ASCE Engineering Mechanics Conference 11 (2004)

[13.] Al-Khalili, A.M., Ali, A.S., Al-Taie, A.J., Effect of metakaolin and silica fume on the engineering properties of expansive soil. IOP Conference Series: Material Science and Engineering (2021).

[14.] Tiwari, N.; Satyam, N., Experimental study on the influence of polypropylene fiber on the swelling pressure expansion attributes of silica fume stabilized clayey soil. Geosciences 9 (2019) 377.

[15.] Abass, I.K., Studying some of the geotechnical properties of stabilized Iraqi clayey soils. Engineering and Technology Journal 31 (2013) 1117-1130.

[16.] Kalkan, E., Akbulut, S., Positive effects of silica fume on the permeability, swelling pressure and compressive strength of natural clay liners. Engineering Geology 73 (2004) 145-56.

[17.] Al-Hassany, H.M., Khalil, W.I., Danha, L.S., Mechanical properties of reactive powder concrete with various steel fiber and silica fume contents. Acta Tehnica Corviniensis - Bulletin of Engineering Tome 7 (2014)
[18.] Bharadwaj, S.,Trivedi, M., Impact of micro silica fume on engineering properties of expansive soil. International Journal of Science Technology \& Engineering 2(12) (2016) 435-440.

[19.] ASTM D2487, Standard practice for Classification of Soils for Engineering Purposes (Unified Soil Classification System, Book of Standards Volume: 04.08 (2017)

[20.] ASTM D698, Standard practice for laboratory compaction characteristics of soil using standard effort (12 $400 \mathrm{ft}-\mathrm{lbf} / \mathrm{ft} 3$ (600 $\mathrm{kN}-\mathrm{m} / \mathrm{m} 3)$ ), Book of Standards Volume: 04.08 (2017).

[21.] ASTM D854, Standard practice for Specific Gravity of Soil Solids by Water Pycnometer, Book of Standards Volume: 04.08 (2017).

[22.] ASTM D4318, Standard practice for Liquid Limit, Plastic Limit, and Plasticity Index of Soils, Book of Standards Volume: 04.08 (2017).

[23.] ASTM D2435, Standard practice for One-Dimensional Consolidation Properties of Soils, Book of Standards Volume: 04.08 (2017).

\section{How to Cite This Article}

Al-Kalil, A., Ali, A., and Al-Taie, A., Some Geotechnical Properties of Clay Soil Enhanced with Silica Fume, Civil Engineering Beyond Limits, 3(2021), 8-11. https://doi.org/10.36937/cebel.2021.003.002 